\title{
Calagem e o Potencial de Lixiviação de Imazaquin em Colunas de SOLO ${ }^{1}$
}

\author{
Liming and Imazaquin Leaching Potential in Soil Columns \\ INOUE, M.H. ${ }^{2.4}$, MARCHIORI JR., O. ${ }^{2}$, OLIVEIRA Jr., R.S. ${ }^{3.4}$, CONSTANTIN, J. ${ }^{3}$ e \\ TORMENA, C.A. ${ }^{3}$
}

\begin{abstract}
RESUMO - Com o objetivo de avaliar o potencial de lixiviação do herbicida imazaquin em colunas de solo, após a aplicação de diferentes níveis de calagem em amostras de Latossolo Vermelho Distrófico (LV) (arenoso) e Latossolo Roxo Distroférrico (LR) (argiloso), foram conduzidos dois ensaios em casa de vegetação, no período de março a dezembro de 1999. Os ensaios consistiram da aplicação de imazaquin $\left(150 \mathrm{~g} \mathrm{ha}^{-1}\right)$ no topo das colunas, cujos solos, após receberem os diferentes níveis de calagem, apresentavam diferentes valores de $\mathrm{pH}$. A seguir, simulou-se uma chuva de $30 \mathrm{~mm}$ (LV) ou $90 \mathrm{~mm}$ (LR) no topo das colunas. Três dias após, foram instalados bioensaios com pepino (LV), lentilha e sorgo (LR), distribuindo-se as sementes em sulco ao longo das colunas, para avaliar a lixiviação do imazaquin. Os resultados evidenciaram que o incremento no nível de calagem proporcionou significativo aumento do potencial de lixiviação de imazaquin nas colunas de ambos os solos. Constatou-se também que o sorgo foi mais sensivel que a lentilha como bioindicador da atividade de imazaquin.
\end{abstract}

Palavras-chave: bioensaio.

\begin{abstract}
Two greenhouse experiments were carried out from March to December 1999, to evaluate the leaching potential of imazaquin in soil columns, after applying different levels of liming in samples of Red Latosol Dystrophyc (LV) and Dusky Red Latosol (LR). The experiments consisted basically in spraying imazaquin (150 $\left.\mathrm{g} \mathrm{ha}^{-1}\right)$ on the top of columns filled with soils with different levels of liming, what caused them to be at different final $\mathrm{pH}$ values. After spraying, a simulated rainfall of $30 \mathrm{~mm}(\mathrm{LV})$ or $90 \mathrm{~mm}(L R)$ was applied to the top of the columns. Three days later, cucumber (LV), lentil and sorghum (LR) seeds were distributed in a central furrow along the columns, and bioassays were performed to detect imazaquin leaching. The results showed that increasing liming levels resulted in a significantly higher leaching potential of imazaquin in soil columns. Sorghum was more sensitive than lentil as a bioindicator of imazaquin activity.
\end{abstract}

Key words: bioassay.

\section{INTRODUÇÃO}

A utilização de herbicidas tem contribuído de maneira substancial para a expansão e o desenvolvimento da agricultura brasileira. Essa classe de pesticidas representa atualmente cerca de 56\% do volume total de negócios com pesticidas no Brasil (Oliveira Jr., 2001). Um exemplo claro da importância dos herbicidas na agricultura brasileira relaciona-se à utilização desses insumos nas áreas de plantio direto. A utilização de herbicidas, na safra 98/99, viabilizou a adoção desse sistema de plantio em mais de 13 milhões de hectares (FEBRAPDP, 2001).

Recebido para publicação em 29/6/2001 e na forma revisada em 17/12/2001.

2 Estudante de mestrado do Curso de Pós-Graduação em Agronomia; ${ }^{3}$ Prof. Adjunto do Departamento de Agronomia da Universidade Estadual de Maringá, Av. Colombo, 5790, 87020-900 Maringá-PR; ${ }^{4}$ Bolsista do CNPq. 
Devido à necessidade de uso racional dos insumos agrícolas para minimizar os impactos ambientais da agricultura, muitos estudos têm sido realizados com o objetivo de compreender o comportamento de herbicidas no solo. No entanto, pouco se sabe a respeito do comportamento desses pesticidas em solos tropicais. A correlação entre as características inerentes a esses solos, como a presença de cargas dependentes de $\mathrm{pH}$, a predominância de minerais de argila 1:1 e óxidos de ferro e alumínio e a grande importância da matéria orgânica na CTC total do solo, e o destino de herbicidas no ambiente é escassamente abordada em trabalhos publicados até o momento. Evidências recentes indicam que esses fatores podem ser de grande relevância no que se refere aos principais mecanismos que controlam o destino final dessas moléculas no solo (Costa et al., 2000; Rocha et al., 2000; Albuquerque et al., 2001).

Particularmente no caso de solos brasileiros, pouco se sabe a respeito da influência que a calagem exerce sobre a retenção e o movimento de herbicidas e, por conseqüência, na sua eficácia e no potencial de lixiviação.

O imazaquin é um herbicida iônico, do grupo químico das imidazolinonas, intensamente utilizado em aplicações em pré-emergência na cultura da soja. Seu comportamento no solo é basicamente controlado pelo $\mathrm{pH}$ do meio (Stougaard et al., 1990; Regitano et al., 1997), o qual exerce efeito inversamente proporcional sobre sua sorção (Goetz et al., 1986; Loux et al., 1989; Stougaard et al., 1990). Assim, fatores que contribuam para a mudança do balanço final de cargas nos solos tropicais, como a calagem, devem ser estudados do ponto de vista de sua influência na sorção e no movimento das moléculas de imazaquin no solo.

Dentre as técnicas analíticas que permitem a identificação e quantificação de resíduos de herbicidas no solo e na água, destacam-se o uso de radioisótopos e a cromatografia líquida e gasosa. Uma técnica alternativa é a utilização de espécies vegetais que apresentam alta sensibilidade ao herbicida de interesse, denominadas bioindicadores. Embora não exista uma espécie única capaz de ser considerada adequada para vários herbicidas (Cole \& Canning, 1993), o sorgo e o pepino têm sido constantemente utilizados para este fim (Caetano et al.,
1995; Pires et al.,1997; Jettner et al., 1999), inclusive para detecção de herbicidas do grupo das imidazolinonas (Vizantinopoulos \& Lolos, 1994; Flint \& Witt, 1997; Rabaey \& Harvey, 1997; Elazzouzi et al., 1998; Silva et al., 1999a; Silva et al., 1999b). Com menor freqüência, também a lentilha é usada com essa finalidade (Pool \& Du Toit, 1995).

Em razão da escassez de informações quanto ao potencial de movimentação do imazaquin em solos brasileiros, evidencia-se a necessidade de pesquisas sobre o comportamento deste herbicida em solos cultivados com o uso da calagem. Nesse contexto, o objetivo deste trabalho foi avaliar, em colunas de solo, o potencial de lixiviação do imazaquin em duas classes de solo cultivado no Brasil, após a aplicação de diferentes níveis de calagem, utilizando bioindicadores como técnica de detecção.

\section{MATERIAL E MÉTODOS}

Foram conduzidos dois experimentos em casa de vegetação, com amostras de solo provenientes da profundidade de $100-150 \mathrm{~cm}$, de modo a evitar a influência do maior conteúdo de matéria orgânica da camada superficial. Os solos estudados foram classificados como Latossolo Vermelho Distrófico e Latossolo Roxo Distroférrico (EMBRAPA, 1999). A origem e as caracterizações químicas e físicas das amostras de solo utilizadas nas colunas encontram-se nas Tabelas 1 e 2.

Tabela 1 - Origem e características físicas dos solos utilizados nas colunas

\begin{tabular}{|l|c|c|}
\hline \multicolumn{1}{|c|}{ Características } & $\begin{array}{c}\text { Latossolo Vermelho } \\
\text { Distrófico }\end{array}$ & $\begin{array}{c}\text { Latossolo Roxo } \\
\text { Distroférrico }\end{array}$ \\
\hline Local de coleta & Maringá-PR & Mandaguari-PR \\
Material de origem & Arenito Caiuá & Basalto \\
Areia $\left(\mathrm{g} \mathrm{kg}^{-1}\right)$ & 640 & 110 \\
Silte $\left(\mathrm{g} \mathrm{kg}^{-1}\right)$ & 10 & 240 \\
Argila $\left(\mathrm{g} \mathrm{kg}^{-1}\right)$ & 350 & 650 \\
Textura & Média & Argilosa \\
\hline
\end{tabular}

Os solos foram peneirados ( $2 \mathrm{~mm}$ ) e acondicionados em sacos plásticos, para receberem diferentes níveis de calagem. Foram calculadas e adicionadas aos sacos plásticos quantidades 
de calcário dolomítico (PRNT=87\%) suficientes para os niveis de calagem equivalentes aos descritos na Tabela 3. Após mistura e homogeneização do calcário ao solo, as amostras foram mantidas, durante os 90 dias subseqüentes, com umidade suficiente para permitir a reação de neutralização do solo. Os pHs resultantes após o período de incubação encontram-se também na Tabela 3.

O solo foi acondicionado em colunas de PVC (40 cm de altura e $10 \mathrm{~cm}$ de diâmetro) previamente seccionadas longitudinalmente. Para manter as duas metades da coluna unidas, estas foram amarradas com arame liso e recobertas interna e externamente com parafina. Cada coluna recebeu, de forma manual e cuidadosamente, $2,5 \mathrm{~kg}$ de solo. Após o acondicionamento, as colunas foram umedecidas por capilaridade por um período de 10 horas, até que o solo se apresentasse saturado até o topo da coluna. A seguir, as colunas foram mantidas na bancada da casa de vegetação por 24 horas, para que o excesso de água fosse drenado.

O herbicida imazaquin foi aplicado ao topo das colunas na dose de $150 \mathrm{~g} \mathrm{ha}^{-1}$, utilizandose de um pulverizador com pressão constante, à base de $\mathrm{CO}_{2}$, munido de quatro bicos do tipo leque 110.02 , espaçados entre si de $0,50 \mathrm{~m}$, aplicando-se um volume de calda equivalente a $200 \mathrm{~L} \mathrm{ha}^{-1}$. No momento da aplicação, as colunas foram posicionadas de modo que o topo delas estivesse sempre $50 \mathrm{~cm}$ abaixo da altura da barra de aplicação. A seguir, foi aplicada no topo das colunas quantidade de água suficiente para simular precipitações de $30 \mathrm{~mm}$ (ensaio com amostras de Latossolo Vermelho Distrófico) e $90 \mathrm{~mm}$ (ensaio com amostras de Latossolo Roxo Distroférrico). Esses níveis de precipitação foram estabelecidos em ensaios preliminares, que indicaram a lâmina de chuva necessária para que um corante adicionado ao topo da coluna percolasse até a outra extremidade. Três dias após a aplicação, as colunas tiveram as duas metades separadas longitudinalmente, de forma que cada metade se tornou uma unidade experimental. Vinte e quatro horas após a abertura das colunas, os bioindicadores foram semeados em sulco no centro da coluna, a $1 \mathrm{~cm}$ de profundidade.

Tabela 3 - Níveis de calagem utilizados e pH final dos dois solos utilizados nos ensaios

\begin{tabular}{|c|c|c|c|c|c|}
\hline \multicolumn{3}{|c|}{ Latossolo Vermelho Distrófico } & \multicolumn{3}{|c|}{ Latossolo Roxo Distroférrico } \\
\hline \multirow{2}{*}{$\begin{array}{c}\text { Níveis de } \\
\text { calagem } \\
\left(\mathrm{t} \mathrm{ha}^{-1}\right)\end{array}$} & \multicolumn{2}{|c|}{$\mathrm{pH}$ final } & \multirow{2}{*}{$\begin{array}{l}\text { Níveis de } \\
\text { calagem } \\
\left(\mathrm{t} \mathrm{ha}^{-1}\right)\end{array}$} & \multicolumn{2}{|c|}{$\mathrm{pH}$ final } \\
\hline & $\mathrm{H}_{2} \mathrm{O}$ & $\mathrm{CaCl}_{2}$ & & $\mathrm{H}_{2} \mathrm{O}$ & $\mathrm{CaCl}_{2}$ \\
\hline 0,00 & 4,60 & 4,20 & 0,00 & 4,78 & 4,37 \\
\hline 0,75 & 5,00 & 4,70 & 1,00 & 4,91 & 4,63 \\
\hline 1,50 & 5,15 & 5,00 & 2,00 & 5,30 & 5,24 \\
\hline 2,25 & 5,40 & 5,20 & 3,00 & 5,90 & 5,70 \\
\hline 3,00 & 6,00 & 5,70 & 4,00 & 6,00 & 5,79 \\
\hline
\end{tabular}

No ensaio 1 foi utilizado o pepino (Cucumis sativus) como espécie bioindicadora, com amostras provenientes do Latossolo Vermelho Distrófico. No ensaio 2, com amostras de Latossolo Roxo Distroférrico, utilizaram-se lentilha (Lens esculenta) e sorgo (Sorghum bicolor), tendo em vista resultados de ensaios paralelos visando a determinação da espécie mais sensível como bioindicador (Marchiori Jr. et al., 2000).

Decorridos 14 dias da semeadura, avaliouse o número de plantas vivas de pepino a partir do topo das colunas. No ensaio 2 , decorrido esse período, as colunas foram previamente divididas em três secções de igual tamanho (Figura 1) e determinou-se a biomassa seca da parte aérea

Tabela 2 - Características químicas e físicas de amostras de solos utilizadas nas colunas

\begin{tabular}{|c|c|c|c|c|c|c|c|c|c|c|c|}
\hline \multirow{2}{*}{ Ensaio } & \multicolumn{2}{|c|}{$\mathrm{pH}$} & $\mathrm{Al}^{3+}$ & $\mathrm{H}^{+}+\mathrm{Al}^{3+}$ & $\mathrm{Ca}^{+2}+\mathrm{Mg}^{2+}$ & $\mathrm{Ca}^{2+}$ & $\mathrm{K}^{+}$ & \multirow{2}{*}{$\frac{P}{\left(\mathrm{mg} \mathrm{dm}^{-3}\right)}$} & \multirow{2}{*}{$\frac{C}{\left(\mathrm{~g} \mathrm{dm}^{-3}\right)}$} & \multirow{2}{*}{$\frac{\text { CTC }}{\left(\mathrm{cmol}_{\mathrm{c}} \mathrm{dm}^{-3}\right)}$} & \multirow{2}{*}{$\frac{\mathrm{V}}{(\%)}$} \\
\hline & $\mathrm{CaCl}_{2}$ & $\mathrm{H}_{2} \mathrm{O}$ & \multicolumn{5}{|c|}{$\left(\mathrm{cmol}_{\mathrm{c}} \mathrm{dm}^{-3}\right)$} & & & & \\
\hline $\mathrm{LV}^{1 /}$ & 4,2 & 4,6 & 1,10 & 3,36 & 0,85 & 0,48 & 0,03 & 1 & 1,88 & 4,24 & 20,8 \\
\hline $\mathrm{LR}^{2 !}$ & 4,4 & 4,8 & 0,00 & 4,61 & 4,58 & 2,47 & 0,42 & 1 & 12,28 & 9,61 & 52,0 \\
\hline
\end{tabular}

${ }^{1 /} \mathrm{LV}=$ Latossolo Vermelho Distrófico.

${ }^{2 /} \mathrm{LR}=$ Latossolo Roxo Distroférrico. 
das espécies bioindicadoras utilizadas (lentilha e sorgo), por secção de coluna. Para cada secção, os dados foram convertidos em porcentagem de biomassa, em relação ao total de biomassa produzida na unidade experimental.

A análise de dados foi feita separadamente para cada tipo de solo, considerando-se os niveis de calagem como tratamentos. No ensaio 1 , foi feito também um tratamento adicional, usandose quatro vezes a dose de imazaquin (600 $\left.\mathrm{g} \mathrm{ha}^{-1}\right)$ aplicada em colunas com solo sem calagem. Ambos os ensaios foram conduzidos com seis repetições, em delineamento inteiramente casualizado, utilizando-se o SAEG para a análise estatística (SAEG, 1997). Nos casos pertinentes, os dados foram discutidos por meio de análise descritiva, utilizando os parâmetros média e desvio-padrão. Em alguns casos, os dados foram submetidos à análise de regressão e o ajuste dos modelos foi feito com base no critério da significância a 5\% de probabilidade de seus coeficientes pelo teste $t$. Os modelos utilizados foram os seguintes:

Ensaio 1: $\mathrm{NPV}=\mu+\mathrm{NC}_{\mathrm{i}}+\mathrm{e}_{\mathrm{ij}}$

Ensaio 2: $\mathrm{B}=\mu+\mathrm{NC}_{\mathrm{i}}+\mathrm{NC}_{\mathrm{i}}^{2}+\mathrm{e}_{\mathrm{ijk}}$

em que NPV = número de plantas vivas; $\mathrm{B}=\%$ de biomassa da planta-teste em relação à testemunha sem herbicida; $\mu=$ média geral; $\mathrm{NC}_{\mathrm{i}}=$ iésimo nível de calagem; $\mathrm{e}_{\mathrm{ij}}=$ erro (ensaio 1); $\mathrm{e}_{\mathrm{ijk}}=$ erro (ensaio 2).

\section{RESULTADOS E DISCUSSÃO}

\section{Ensaio 1}

A profundidade até a qual os sintomas de toxicidade nas plantas de pepino foram observados foi influenciada pelos diferentes níveis de calagem realizados no Latossolo Vermelho Distrófico (Figura 2). De acordo com Mangels (1991), o imazaquin, por se tratar de um herbicida ionizável, pode apresentar-se em duas formas quanto à sua carga líquida; abaixo de $\mathrm{pH}$ de 3,8, a forma predominante é a molecular, cuja carga líquida é zero. Quando o pH do solo se aproxima da neutralidade, passa a predominar a forma aniônica, diminuindo a força de atração entre moléculas do herbicida e as cargas predominantes no solo. Desse comportamento resulta uma menor sorção do herbicida e, conseqüentemente, maior lixiviação deste no solo.
Os resultados indicam que a quantidade de imazaquin lixiviada foi modificada pelo $\mathrm{pH}$ final do solo nas colunas. À medida que se aumentou o nível de calagem, a sorção foi menos intensa, resultando no aumento da lixiviação do herbicida aplicado, o que foi evidenciado pela morte/ deformação de plantas de pepino em toda a extensão da coluna nos níveis de calagem de 2,25 e 3,00 tha-1 (secções de coluna E e F da Figura 2).

Constatou-se que a sobrevivência das plantas de pepino foi drasticamente afetada pela lixiviação de imazaquin, resultando num decréscimo linear do número de plantas vivas com a elevação do nível de calagem (Figura 3).

A hipótese de que a lixiviação de imazaquin foi a principal responsável pela morte das plantas bioindicadoras também é subsidiada pela análise da Figura 4. Mesmo quando o imazaquin foi aplicado no topo das colunas numa dose de $600 \mathrm{~g} \mathrm{ha}^{-1}$ (equivalente a quatro vezes a dose recomendada de $150 \mathrm{~g} \mathrm{ha}^{-1}$ ), não se observou lixiviação e morte das plantas de pepino em grande extensão na coluna (Figura 4), ou seja, sob condições de elevada acidez do solo, mesmo quando a dose de imazaquin foi quadruplicada, a morte de plantas ficou restrita à parte superficial das colunas. Tomando-se como referência a secção da coluna que não recebeu calagem nem aplicação de imazaquin (A), a comparação de colunas que receberam calagem e a dose normal de imazaquin (B e C) com aquelas que não receberam calagem e dose $4 \mathrm{x}$ do herbicida (D) sugere que o principal fator que determinou a morte das plantas foi a lixiviação do herbicida, provavelmente causada pela alteração do $\mathrm{pH}$ do solo e ionização do herbicida.

\section{Ensaio 2}

Constatou-se que a calagem influencia, em grande intensidade, o movimento do imazaquin nas colunas de solo, independentemente da espécie bioindicadora utilizada (Tabela 4). Assim, niveis mais elevados de calagem apresentam maior potencial de lixiviação deste herbicida do que os niveis mais baixos. Rocha et al. (2000) observaram que a elevação do pH também diminuiu em grande intensidade a sorção de imazaquin em um Latossolo Vermelho Acriférrico, o que subsidia os fatos aqui observados. 
Aplicação do herbicida ת

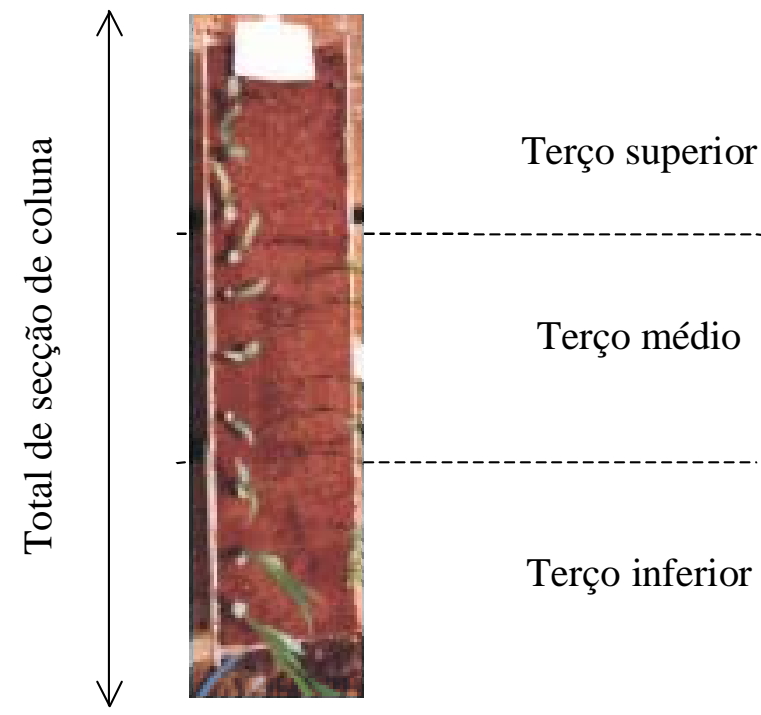

Figura 1 - Divisão realizada nas colunas para determinação de biomassa seca da parte aérea das plantas bioindicadoras (ensaio 2).

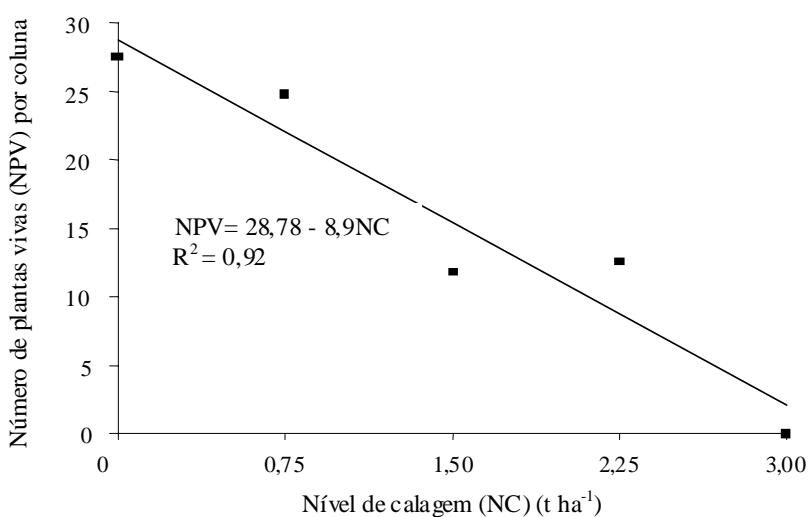

Figura 3 - Número de plantas vivas (NPV) de pepino observado sob diferentes níveis de calagem (NC) do solo (LV) em colunas que receberam a aplicação do herbicida imazaquin (150 $\mathrm{g} \mathrm{ha}^{-1}$ ) (ensaio 1).

Na Figura 5, observa-se que o aumento das doses de calcário reduziu a produção de biomassa seca em relação à testemunha, em todas as partes da coluna analisada, sendo essa redução mais acentuada no terço superior da coluna.

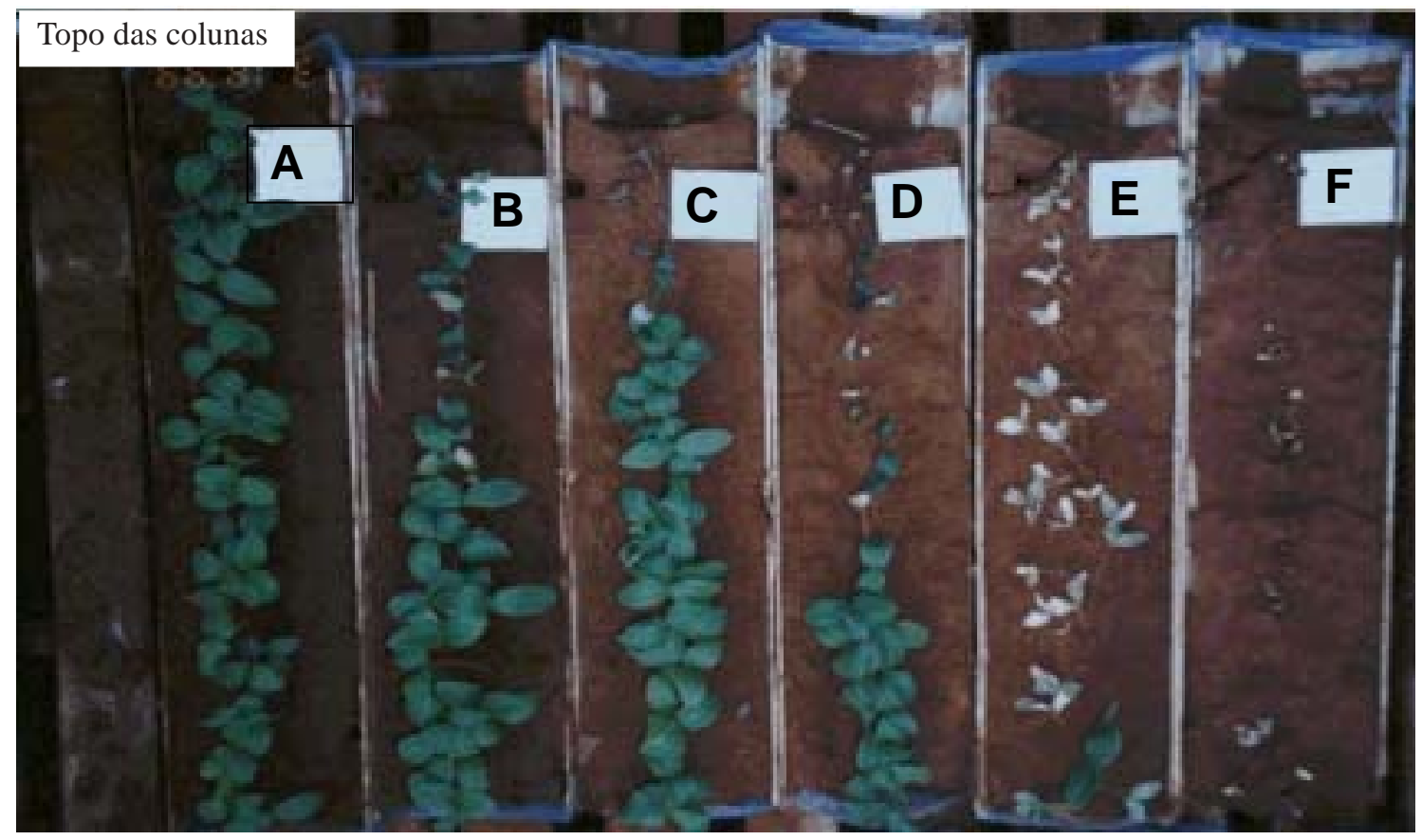

Figura 2 - Aspecto geral das plantas bioindicadoras (pepino) nas colunas de solo (LV) em função do nível de calagem (NC). A= testemunha sem herbicida, sem calagem e $\mathrm{pH}=4,2$. De B até $\mathrm{F}$ as letras indicam os seguintes níveis de calagem $\left(\mathrm{t} \mathrm{ha} \mathrm{a}^{-1}\right)$ e $\mathrm{pHs}$ finais, após a aplicação de $150 \mathrm{~g} \mathrm{ha}^{-1}$ de imazaquin: $\mathrm{B}(\mathrm{NC}=$ zero; $\mathrm{pH}=4,2), \mathrm{C}(\mathrm{NC}=0,75 ; \mathrm{pH}=4,7), \mathrm{D}(\mathrm{NC}=1,50 ; \mathrm{pH}=5,0)$, $\mathrm{E}(\mathrm{NC}=2,25 ; \mathrm{pH}=5,2)$ e $\mathrm{F}(\mathrm{NC}=3,00 ; \mathrm{pH}=5,7)$ (ensaio 1$)$. 


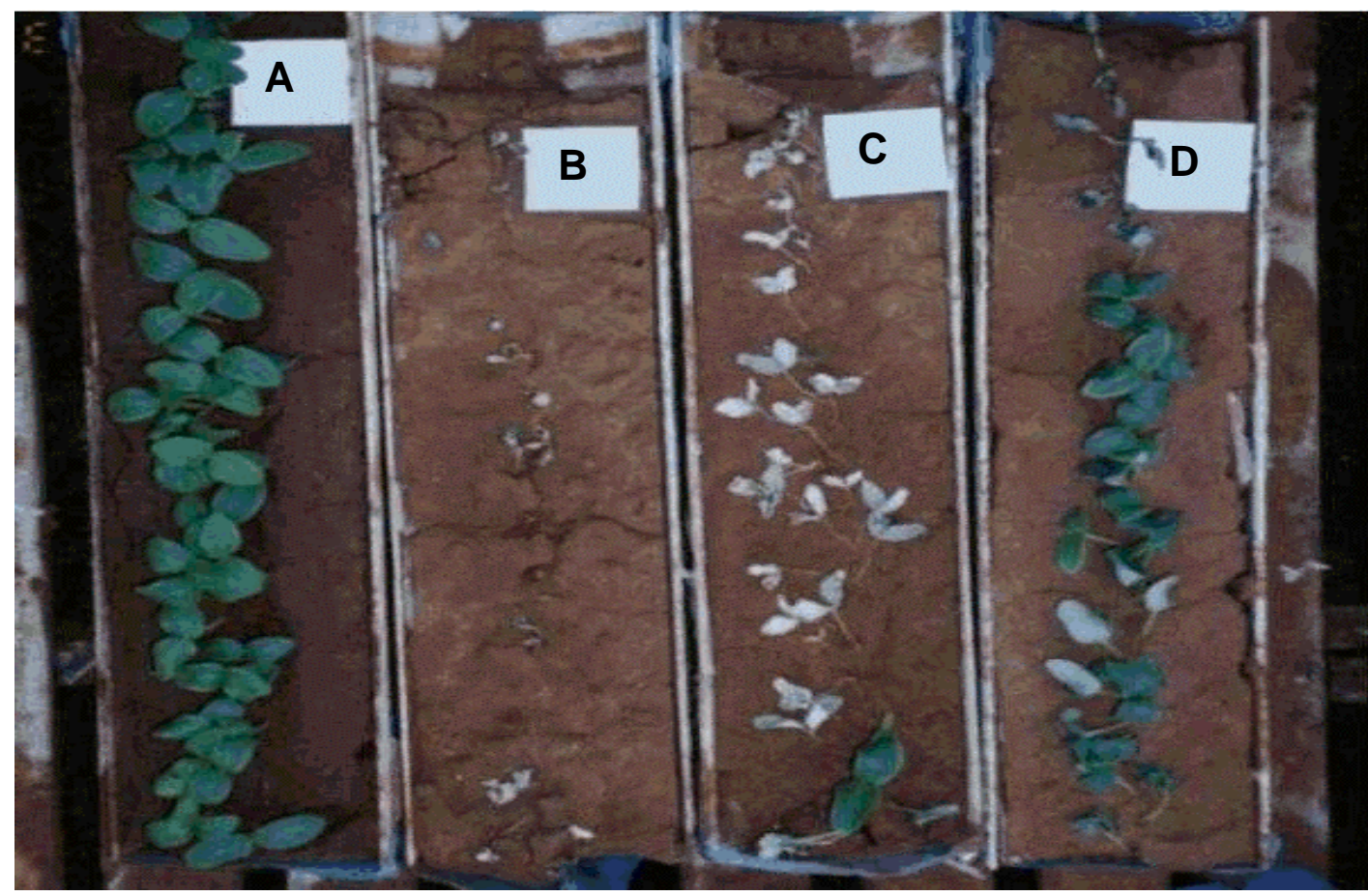

Figura 4 - Aspecto geral das plantas bioindicadoras (pepino) nas colunas de solo (LV) em função de doses de imazaquin e nível de calagem. As letras indicam: $A=$ testemunha sem herbicida, sem calagem; $\mathrm{B}$ e $\mathrm{C}=$ receberam calagem $\left(3,00\right.$ e $2,25 \mathrm{t} \mathrm{ha}^{-1}$, respectivamente) e dose de $150 \mathrm{~g} \mathrm{ha}^{-1} ; \mathrm{D}=$ sem calagem e dose de $600 \mathrm{~g} \mathrm{ha}^{-1}$ (ensaio 1 ).

Tabela 4 - Porcentagem de produção de biomassa seca da parte aérea, após a aplicação de imazaquin $\left(150 \mathrm{~g} \mathrm{ha}^{-1}\right)$ no LR (ensaio 2)

\begin{tabular}{|c|c|c|c|c|c|c|}
\hline \multirow{2}{*}{$\begin{array}{c}\text { Níveis de calagem } \\
\left(\mathrm{t} \mathrm{ha}^{-1}\right)\end{array}$} & \multicolumn{3}{|c|}{ Biomassa de sorgo } & \multicolumn{3}{c|}{ Biomassa de lentilha } \\
\cline { 2 - 7 } & Total & Superior & Inferior & Total & Superior & Inferior \\
\hline $0^{*}$ & $84,82 \pm 17,13$ & $89,94 \pm 29,79$ & $87,49 \pm 37,02$ & $89,80 \pm 22,03$ & $98,86 \pm 37,19$ & $96,01 \pm 37,62$ \\
1 & $73,99 \pm 29,15$ & $73,51 \pm 31,30$ & $85,79 \pm 39,75$ & $103,98 \pm 16,72$ & $71,22 \pm 16,97$ & $92,10 \pm 5,99$ \\
2 & $73,48 \pm 22,53$ & $60,04 \pm 34,63$ & $77,75 \pm 31,76$ & $85,34 \pm 16,61$ & $69,22 \pm 36,22$ & $64,63 \pm 27,46$ \\
3 & $70,57 \pm 23,56$ & $42,77 \pm 30,64$ & $64,46 \pm 26,05$ & $64,21 \pm 16,17$ & $66,76 \pm 24,46$ & $54,31 \pm 12,72$ \\
4 & $34,89 \pm 10,09$ & $19,79 \pm 15,17$ & $40,07 \pm 20,93$ & $58,23 \pm 6,25$ & $38,48 \pm 20,53$ & $23,15 \pm 2,37$ \\
\hline
\end{tabular}

* Em relação à testemunha sem herbicida.
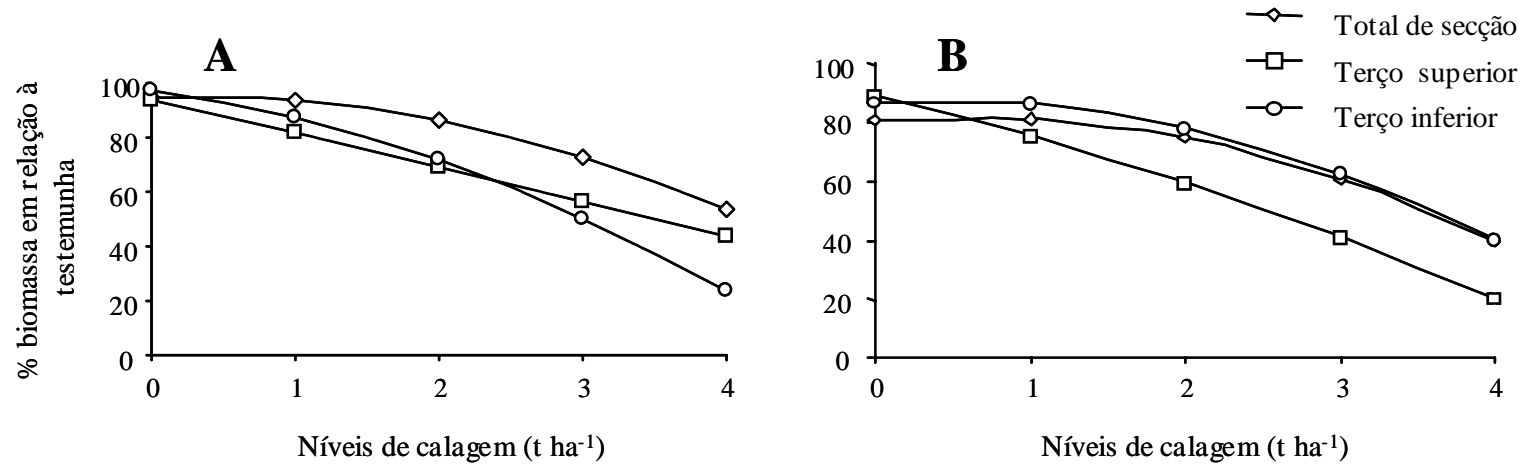

Figura 5 - Curvas do acúmulo da biomassa (\% em relação à testemunha sem herbicida), após a aplicação de imazaquin na dose de $150 \mathrm{~g} \mathrm{ha}^{-1}$ no LR, nas espécies bioindicadoras lentilha (A) e sorgo (B). As equações ajustadas e os respectivos coeficientes de ajuste $\left(\mathrm{R}^{2}\right)$ encontram-se na Tabela 5 (ensaio 2). 
Tabela 5 - Parâmetros das análises de regressão do efeito da calagem na lixiviação de imazaquin e conseqüente acúmulo de biomassa dos bioindicadores nas colunas de solo (LR) (ensaio 2)

\begin{tabular}{|l|l|c|c|c|}
\hline Espécies & \multicolumn{1}{|c|}{ Biomassa } & Equações & $\mathrm{R}^{2}$ & $\mathrm{NC}_{50} *\left(\mathrm{t} \mathrm{ha}^{-1}\right)$ \\
\hline Lentilha & Total de secção de coluna & $\mathrm{B}=94,78+(1,9404 \mathrm{NC})-\left(3,05786 \mathrm{NC}^{2}\right)$ & 0,84 & $>4,00$ \\
Lentilha & Terço superior & $\mathrm{B}=93,79-(12,1020 \mathrm{NC})-\left(0,10999 \mathrm{NC}^{2}\right)$ & 0,86 & 3,51 \\
Lentilha & Terço inferior & $\mathrm{B}=97,41-(7,6795 \mathrm{NC})-\left(2,66786 \mathrm{NC}^{2}\right)$ & 0,97 & 3,01 \\
\hline Sorgo & Total de secção de coluna & $\mathrm{B}=80,76+(4,5577 \mathrm{NC})-\left(3,72143 \mathrm{NC}^{2}\right)$ & 0,87 & 3,55 \\
Sorgo & Terço superior & $\mathrm{B}=89,00-(12,2754 \mathrm{NC})-\left(1,20715 \mathrm{NC}^{2}\right)$ & 0,99 & 2,54 \\
Sorgo & Terço inferior & $\mathrm{B}=87,11+(2,8487 \mathrm{NC})-\left(3,61643 \mathrm{NC}^{2}\right)$ & 0,99 & 3,62 \\
\hline
\end{tabular}

$* \mathrm{NC}_{50}=$ nível de calagem necessário para que haja 50\% de redução na biomassa da espécie bioindicadora.

Nas equações, B identifica a biomassa seca da parte aérea dos bioindicadores (\% em relação à testemunha) e NC representa os níveis de calagem aplicados $\left(\mathrm{t} \mathrm{ha}^{-1}\right)$.

Ao comparar os valores de porcentagem de biomassa seca obtidos com a utilização de plantas de sorgo e de lentilha (Tabela 4), observase que, em geral, o sorgo apresentou maior sensibilidade como bioindicador da lixiviação de imazaquin, uma vez que, através das equações estabelecidas (Tabela 5), determinou-se que menores niveis de calagem $\left(\mathrm{NC}_{50}\right)$ são necessários para reduzir o acúmulo de biomassa em $50 \%$, tanto para a secção de coluna quanto para os terços superior e inferior.

Considerando os resultados gerais obtidos em ambos os ensaios, constata-se que, mesmo num solo argiloso, como o LR, a lixiviação do imazaquin pode ser significativa após a calagem. Embora a sorção deste herbicida no solo também seja correlacionada ao teor de argila (Loux et al., 1989; Regitano et al., 1997; Rocha et al., 2000), a maioria dos trabalhos publicados tem concluído que o efeito do $\mathrm{pH}$ é maior e mais importante que o fator teor de argila no solo.

Admite-se que, em condições normais, a quantidade de herbicida perdida pelo movimento da molécula no perfil do solo seja bastante restrita, sendo geralmente inferior a $1 \%$ do total aplicado (Carter, 2000). No entanto, para o caso de herbicidas derivados de ácidos fracos, como o imazaquin, parece que, sob condições de $\mathrm{pH}$ do solo tendendo à neutralidade, uma lixiviação muito mais significativa ocorre, o que pode afetar tanto a atividade do herbicida com relação ao controle de plantas daninhas, como também sua persistência no solo e no ambiente.

A lixiviação de pesticidas no perfil do solo tem também implicações diretas no seu potencial de contaminação dos recursos hídricos do subsolo, já que, uma vez retirado das camadas superficiais de solo, onde há maior teor de matéria orgânica e atividade microbiana, a sua persistência pode ser prolongada (Sarmah et al., 1999; Costa et al., 2000; Prata et al., 2000; Albuquerque et al., 2001).

Contudo, embora a lixiviação nas colunas de solo tenha sido intensa, especialmente em valores de $\mathrm{pH}$ mais próximos da neutralidade, trabalhos no campo têm evidenciado movimentação limitada de imazaquin no perfil do solo (Zeleznik et al., 1992). Esse fato deve-se, provavelmente, à presença de maior quantidade de matéria orgânica nos primeiros centímetros da camada superficial e à indeformação da estrutura no perfil do solo.

\section{AGRADECIMENTOS}

Ao CNPq, pelo apoio financeiro, e aos funcionários do Laboratório de Solos do Departamento de Agronomia da Universidade Estadual de Maringá, pela colaboração nas análises dos solos.

\section{LITERATURA CITADA}

ALBUQUERQUE, M. A. et al. Mineralização e sorção de atrazina em Latossolo Roxo sob cultivo convencional e plantio direto. R. Bras. Ci. Solo, v. 25, n. 1, p. 179-188, 2001.

CAETANO, L.C.S. et al. Adsorção e lixiviação do herbicida napropamida em dois Latossolos. Cienc. Prat., v.19, n.2, p.129-134, 1995.

CARTER, A. D. Herbicide movement in soils: principles, pathway and processes. Weed Res., v. 40, n. 1, p. 22-113, 2000 .

Planta Daninha, Viçosa-MG, v.20, n.1, p.125-132, 2002 
COLE, J. F. M.; CANNING, L. Rationale for the choice of species in the regulatory testing of the effects of pesticides on terrestrial non-target plants. In: BRITISH CROP PROTECTION CONFERENCE - WEEDS, 1993, Brighton. Proceedings... Brighton: 1993. p.151-156.

COSTA, M. A.; MONTEIRO, R. T. R.; TORNISIELLO, V. L. Degradação de ametrina em Areia Quartzosa com adição de solo rizosférico de cana-de-açúcar. R. Bras. Ci. Solo, v. 24, n. 1, p. 43-48, 2000.

ELAZZOUZI, M. et al. Study on the behavior of imazapyr in two Moroccan soils. Weed Res., v. 38, p. 217-220, 1998.

\section{EMPRESA BRASILEIRA DE PESQUISA}

AGROPECUÁRIA - EMBRAPA. Centro Nacional de Pesquisa de Solos (Rio de Janeiro, RJ). Sistema Brasileiro de Classificação de Solos. Rio de Janeiro: 1999. 412p.

\section{FEDERAÇÃO BRASILEIRA DE PLANTIO DIRETO NA} PALHA- FEBRAPDP. Brasil - Expansão da área cultivada em plantio direto. [S.1.: s.n.], 2001. Disponível em: 〈http://www.agri.com.br/febrapdp/pd-area-br.htm>. Acesso em: 20 jun. 2001.

FLINT, J. C.; WITT, W. W. Microbial degradation of imazaquin and imazethapyr. Weed Sci., v. 45, n. 4, p. 586$591,1997$.

GOETZ, A. J. et al. Soil solution and mobility characterization of imazaquin. Weed Sci., v. 34, p. 788-793, 1986.

JETTNER, R.J. et al. Plant sensitivity to atrazine and chlorsulfuron residues in a soil-free system. Weed Res., v. 39, n. 4, p. 287-295, 1999.

LOUX, M. M.; LIEBEL, A.; SLIFE, F. W. Adsorption of imazaquin and imazethapyr on soils, sediments and selected adsorbents. Weed Sci., v. 37, p. 712-718, 1989.

MANGELS, G. Behavior of the imidazolinone herbicides in solil - a review of the literature. In: SHANER, D. L.; O'CONNOR, S. L. (Eds.) The imidazolinone herbicides. Boca Raton: CRC Press, 1991. p. 191-209.

MARCHIORI Jr., O. et al. Seleção de bioindicadores e efeito da calagem no potencial de lixiviação de herbicidas no solo. In: ENCONTRO ANUAL DE INICIAÇÃO CIENTÍFICA, 9, 2000, Londrina. Resumos... Londrina: Universidade Estadual de Londrina, 2000, p. 98.

OLIVEIRA Jr., R.S. Introdução ao controle químico. In: OLIVEIRA Jr., R. S.; CONSTANTIN, J. Plantas daninhas e seu manejo. Guaíba: Agropecuária, 2001. p. 187-205.
PIRES, N.M. et al. Adsorção e lixiviação de trifluralin e imazaquin em diferentes solos. R. Ceres, v. 44, n. 253, p. 300-304, 1997.

POOL, C. F.; DU TOIT, D. Leaching depth of imazamethabenz-methyl and chlorsulfuron + metsulfuron methyl in different soils. Appl. Plant Sci., v. 9, n. 2, p. 4347, 1995 .

PRATA, F. et al. Degradação e adsorção de diuron em solos tratados com vinhaça. R. Bras. Ci. Solo, v. 24, n. 1, p. $217-223,2000$.

RABAEY, T. L.; HARVEY, R. G. Sweet corn (Zea mays) hybrids respond differently to simulated imazethapyr carryover. Weed Technol., v. 11, n. 1, p. 92-97, 1997.

REGITANO, J.B. et al. Retention of imazaquin in soil. Env. Toxicol. Chem., v. 16, n. 3, p. 397-404, 1997.

ROCHA, W.S.B. et al. Influência do pH na sorção de imazaquin em um Latossolo Vermelho Acriférrico. R. Bras. Ci. Solo, v. 24, p. 649-655, 2000.

SISTEMA PARA ANÁLISES ESTATÍSTICAS - SAEG. Versão 7.0, Viçosa, MG: Fundação Arthur Bernardes, 1997.

SARMAH, A. K.; KOOKANA, R. S.; ALSTON, A. M. Degradation of chlorsulfuron and triasulfuron in alkaline soils under laboratory conditions. Weed Res., v. 39, n. 2, p. 83-94, 1999.

SILVA, A.A. et al. Efeito residual no solo dos herbicidas imazamox e imazethapyr para as culturas de milho e sorgo. Planta Daninha, v. 17, n. 3, p. 345-354, 1999a.

SILVA, A.A. et al. Persistência de herbicidas do grupo das imidazolinonas e efeitos sobre as culturas sucessoras de milho e sorgo. Acta Sci., v. 21, n. 3, p. 459-465, 1999 b.

STOUGAARD, R. N.; SHEA, P. J.; MARTIN, A. R. Effect of soil type and $\mathrm{pH}$ on adsorption, mobility, and efficacy of imazaquin and imazethapyr. Weed Sci., v. 38, p. 67-73, 1990.

VIZANTINOPOULOS, S.; LOLOS, P. Persistence and leaching of the herbicide imazapyr in soil. Bull. Environ. Contam. Toxicol., v. 52, p. 404-410, 1994.

ZELEZNIK, J. M.; FLINT, J. L.; WITT, W. W. Leaching of imazethapyr within two horizons of a Kentucky soil. In: WEED SCIENCE SOCIETY OF AMERICA ANNUAL MEETING, 32, 1992, Brighton. Abstracts... Brigton: British Crop Protection Conference, 1992. p. 103. 